UDC [303]:4-6

LBC 60.5

\title{
SOCIOLOGICAL MONITORING: EXPERIENCE AND PRACTICE OF THE INSTITUTE OF SOCIOLOGY OF THE NATIONAL ACADEMY OF SCIENCES OF BELARUS
}

\author{
Nikolai N. Leonov \\ Institute of Sociology of the National Academy of Sciences of Belarus, Minsk, Republic of Belarus \\ Elena M. Borodacheva \\ Institute of Sociology of the National Academy of Sciences of Belarus, Minsk, Republic of Belarus
}

Vera M. Zrazikova

Institute of Sociology of the National Academy of Sciences of Belarus, Minsk, Republic of Belarus

Nadezhda N. Malinovskaya

Institute of Sociology of the National Academy of Sciences of Belarus, Minsk, Republic of Belarus

\begin{abstract}
The authors describe and analyze the experience of monitoring research having been conducted by Institute of Sociology of National Academy of Sciences of Belarus over the past 17 years. They state the main features of monitoring as a type of sociological research and under this general point of view analyze the monitoring of the Institute. The researchers specify goals and objectives of the monitoring study, list the procedures included in it and the corresponding functions. The scientific and theoretical base on which the research is conducted is described in the article, in particular, the authors characterize the scientific schools and directions created at the Institute. The paper sets out the methodological principles that form the basis of this monitoring study. The article describes instrumentarium, the groups of studied indicators in the form of blocks of questions indicating the frequency of inclusion of these blocks in the questionnaire. The authors note that the questionnaire also includes one-time questions in accordance with the problems of interest at the moment. They present the procedure of sample design developed at the Institute in detail. The procedure uses the concept of the so-called zone. This concept refers to settlements of a lower administrative level than district centers and includes both the location of the settlement relative to the district center (distance, transport accessibility), and certain socio-economic characteristics of the settlement, which allow more accurately stratify settlements. In particular, the zone is included in the number of quotas. The authors point out features of mathematical analysis of the data, the development of the original mathematical software providing an increase in both the efficiency of data analysis and its methodological level. Using a specific example the study shows the advantages of monitoring as a means of studying social problems. On the basis of the analysis the authors make conclusions regarding the research tasks that can be solved by this monitoring study.

Key words: sociological monitoring, Institute of Sociology, blocks of questions, dynamics, sample frame, data analysis.

УДК [303]:4-6

ББК 60.5

\section{СОЦИОЛОГИЧЕСКИЙ МОНИТОРИНГ: ОПЫТ И ПРАКТИКА ИНСТИТУТА СОЦИОЛОГИИ НАН БЕЛАРУСИ}

\author{
Николай Николаевич Леонов
}

Институт социологии НАН Беларуси, г. Минск, Республика Беларусь 


\section{Елена Михайловна Бородачёва}

Институт социологии НАН Беларуси, г. Минск, Республика Беларусь

\section{Вера Михайловна Зразикова}

Институт социологии НАН Беларуси, г. Минск, Республика Беларусь

\section{Надежда Николаевна Малиновская}

Институт социологии НАН Беларуси, г. Минск, Республика Беларусь

Аннотация. В статье описывается и анализируется опыт реализации мониторингового исследования, проводимого Институтом социологии НАН Беларуси в течение последних 17 лет. Излагаются основные особенности мониторинга как вида социологического исследования, и под этим общим углом зрения анализируется мониторинг Института социологии. Указаны цели и задачи мониторингового исследования, перечислены входящие в него процедуры и соответствующие им функции. Описана научно-теоретическая база, на которой проводится исследование, для чего, в частности, охарактеризованы научные школы и направления, созданные в Институте. Изложены методические принципы, положенные в основу данного мониторингового исследования. Описан инструментарий, перечислены группы изучаемых показателей в форме блоков вопросов с указанием периодичности включения этих блоков в анкеты. Отмечено, что в анкеты включаются также разовые вопросы в соответствии с проблемами, представляющие интерес в данный момент. Подробно излагается процедура проектирования выборочной совокупности, разработанная в Институте. Процедура использует понятие так называемой зоны. Это понятие относится к поселениям более низкого административного уровня, чем районные центры, и включает в себя как расположение данного населенного пункта относительно районного центра (удаленность, транспортная доступность), так и определенные социально-экономические характеристики самого поселения, что позволяет более точно стратифицировать населенные пункты. В частности, зона включается в число квотируемых признаков. Отмечены особенности математического анализа полученных данных, разработка оригинального количественного инструментария, который обеспечивает повышение как оперативности анализа данных, так и его методического уровня. На конкретном примере показаны преимущества мониторинга как средства изучения социальных проблем. На основе проведенного анализа сделаны выводы относительно задач, которые позволяет решать данное мониторинговое исследование.

Ключевые слова: социологический мониторинг, Институт социологии, блоки вопросов, динамика, выборочная совокупность, анализ данных.

Потребности современного быстроизменяющегося мира в достоверной и оперативной информации (данных) по какой-либо проблеме или ситуации постоянно растут. Республика Беларусь в этом плане также не является исключением. Результаты социологических опросов являются неотъемлемой частью системы информационно-аналитического обеспечения всех органов государственной власти. Социологические данные выступают в качестве одного из важных источников информации при разработке и принятии научно обоснованных управленческих решений. Особое место в системе социологической информации принадлежит как раз мониторинговым исследованиям, предоставляющим возможность сопоставления и сравнения информации в динамике с выходом на существенные тренды социально-политической, социально-экономической и социокультурной жизни страны.
Под социологическим мониторингом (лат. monitorius - предостерегающий, предупреждающий) понимается форма организации и проведения социологических исследований, обеспечивающая постоянное получение социологической информации о состоянии определенного социального процесса или ситуации [Грицанов и др. 2003, 585]. В социологии мониторинг - целостная исследовательская система, которая изучает и прослеживает динамику происходящих в обществе перемен. На основе полученных в ходе социологического мониторинга данных о всякого рода изменениях в обществе разрабатывается социальная политика, эффективность которой, как известно, невозможна без активного участия всего населения страны.

Одной из целей мониторингового исследования является конструирование системы показателей, которые точно и достоверно от- 


\section{БЕЛОРУССКАЯ АКАДЕМИЧЕСКАЯ СОЦИОЛОГИЯ}

ражают состояние, тенденции и проблемы социальных явлений или процессов [Левашов 2006; Шадрина 2010]. При проведении социологического мониторинга происходит накопление информации по выделенным показателям и их анализ в динамике, что, в свою очередь, позволяет выявить тенденции социальных изменений, происходящих в обществе.

Социологический мониторинг включает в себя четыре последовательные и взаимосвязанные процедуры, причем каждой процедуре соответствует специфическая функция:

1) сбор социологической информации диагностическая функция (то есть определение состояния изучаемого социального явления или процесса);

2) обобщение и анализ информации - аналитическая функция (в процессе социологического мониторинга социолог сравнивает полученную информацию с уже имеющейся);

3) распространение информации - информационная функция (донесение полученной информации до заинтересованных социальных субъектов);

4) использование информации - управленческая функция (разработка, уточнение и контроль принятых решений на различных уровнях государственной системы).

Конечно, это не полный перечень функциональных возможностей социологического мониторинга. Данный вид социологических исследований также выполняет побудительную (мотивационную), прогностическую функцию, а также функцию социального контроля, социального регулирования и даже образовательную функцию.

Итак, целью социологического мониторинга является получение новой, актуальной и систематизированной социологической информации периодически, через небольшие промежутки времени. Именно поэтому Институт социологии Национальной академии наук Беларуси с 2002 г. проводит мониторинговое исследование общественно-политической ситуации в Республике. Цель его достаточно естественна - отслеживать восприятие социально-экономических, социально-политических и других процессов населением страны, причем делать это в динамике. Инициатором проведения мониторинга был кандидат философс- ких наук, доцент В.Л. Абушенко, занимавший в то время должность заместителя директора Института социологии НАН Беларуси по научной работе. По его выражению «даже не так важно, что отслеживать, как то, что делать это необходимо в динамике». Именно мониторинг социально-политической ситуации является оптимальным методом организации сбора и анализа информации, поскольку целостная и достаточно глубокая интерпретация тех или иных общественно-политических, социально-экономических, социокультурных процессов и явлений может быть достигнута только на сравнительных, регулярно фиксируемых данных, полученных с помощью агрегированных показателей и в достаточно значимом интервале времени.

До введения мониторинговых исследований Институт социологии существовал 12 лет, и в нем сформировался ряд научных школ: школа социологии стратификации, конфликтов и катастроф (основатель - академик НАН Беларуси Е.М. Бабосов); школа социологии труда и экономической социологии (основатель - д.ф.н., заслуженный работник образования Г.Н. Соколова); школа теории и методологии социологических исследований (основатель - д.с.н. С.А. Шавель); школа социологии науки и науковедения (основатель д.с.н. Г.А. Несветайлов). В рамках этих школ сформировались и обрели самостоятельность такие научные направления, как социология девиантного поведения (д.с.н. Н.А. Барановский), социология здравоохранения (к.с.н. В.Р. Шухатович), социология образования (к.с.н. С.Н. Кройтор, к.с.н. С.В. Костюкевич), социология миграционных процессов (к.ф.н. М.И. Артюхин). Эти школы и направления в сочетании с большим опытом проведения эмпирических социологических исследований обеспечили необходимую научно-методическую базу мониторингового исследования и определили круг изучаемых в ходе его проблем.

Социологический мониторинг выступает как метод исследования реальной социальной практики, мира человеческого опыта в его конкретной ситуационной определенности, осмысленного, целесообразного, проживаемого здесь и сейчас. Он направлен на исследование деятельности индивидов как проявления их социальной активности в самых разных 
областях, а также на выявление социальных условий ее осуществления, которые могут как способствовать развитию действий, так и ограничивать их [Фарман 2012]. В данном случае социологический мониторинг можно рассматривать как непрерывный процесс, исследуя результаты которого социолог может расставлять приоритеты и акценты в проведении исследования.

Так как социологический мониторинг является достаточно сложным и структурированным процессом, то главная особенность такого исследования - его многозадачность. В инструментарий мониторинга включаются блоки вопросов, которые актуальны для Республики на протяжении всего периода проведения исследований. В ходе работы ученые Института социологии анализируют различные социальные процессы, которые в той или иной степени могут влиять на социально-экономическую и политическую ситуацию в стране, а также воздействовать на общественные преобразования. Фактически изучаются не только условия труда, социальная мобильность и миграционные процессы, но и отношения людей с органами власти, отношения с
Европой, НАТО, Россией; измеряется уровень доверия населения к государственным службам и власти, измеряется уровень оптимизма белорусов и многое другое.

Важно отметить, что инструментарий социологического мониторинга, проводимого Институтом социологии, включает систему социальных показателей, которая формируется из определенных подсистем (блоков). Основные группы изучаемых показателей (индикаторов) могут быть охарактеризованы в терминах блоков вопросов, перечень которых приведен в таблице.

Используемая система индикаторов позволяет отслеживать объективные условия и образ жизни людей, различные характеристики их поведения с целью предоставления необходимой комплексной информации. Кроме того, есть вопросы, которые включались лишь в одно исследование, поскольку были связаны со спецификой момента, так называемые ситуационные блоки. Примерами таких блоков могут служить вопросы, посвященные годовщине аварии на ЧАЭС, работе органов внутренних дел, «малой родине» и др.

\section{Периодичность блоков вопросов, входящих в мониторинг Института социологии}

\begin{tabular}{|c|c|}
\hline Название блока & Периодичность \\
\hline Социально-демографический блок & Постоянно (раз в полгода) \\
\hline Блок о материальном самочувствии & Постоянно (раз в полгода) \\
\hline Блок по ценностям & Постоянно (раз в полгода) \\
\hline Блок по социальному оптимизму & Постоянно (раз в полгода) \\
\hline Социально-политический блок & Постоянно (раз в полгода) \\
\hline Социально-экономический блок & Постоянно (раз в полгода) \\
\hline $\begin{array}{l}\text { Блок о взаимоотношениях с другими странами и международ- } \\
\text { ными организациями }\end{array}$ & Постоянно (раз в полгода) \\
\hline Блок по образованию & Раз в год \\
\hline Блок по профессиональной деятельности & Раз в год \\
\hline Миграционный блок (внешняя и внутренняя миграция) & Раз в год \\
\hline Блок по экологии & Раз в год \\
\hline Блок по национальности и идентичности & Раз в год \\
\hline Блок по СМИ & Раз в год \\
\hline Блок по науке и инновациям & Раз в 2-3 года \\
\hline Блок по выборам в различные ветви власти & Раз в 2-3 года \\
\hline Блок по защите прав населения & Раз в 2-3 года \\
\hline Блок по здоровью и здоровьесберегающему поведению & Раз в 2-3 года \\
\hline $\begin{array}{l}\text { Блок по семье (семейные установки, распределение ролей в се- } \\
\text { мье и т. д.) }\end{array}$ & Раз в 2-3 года \\
\hline Блок по лидерству & Раз в 2-3 года \\
\hline Блок по религии & Раз в 2-3 года \\
\hline Блок по культуре (видам искусства) & Раз в 2-3 года \\
\hline Блог по отношению к ВОВ & Раз в 2-3 года \\
\hline «Ситуационные» блоки & Постоянно (раз в полгода) \\
\hline
\end{tabular}


Как видно из таблицы, в каждое исследование включаются вопросы, касающиеся социально-демографических характеристик респондентов, их материального самочувствия, ценностных ориентаций и социального оптимизма, отношения к социально-политической и социально-экономической ситуации, а также вопросы о взаимоотношениях с другими странами и международными организациями. Другие блоки, такие как блок по образованию, профессиональной деятельности респондентов, миграционный блок, блок по экологии, блок по национальности и идентичности и блок по СМИ, замеряются с периодичностью раз в год. Реже (2-3 раза в год) задаются вопросы по науке и инновациям, защите прав населения, выборам в различные ветви власти, здоровью и здоровьесберегающему поведению, семье и семейным установкам, лидерству, религии, культуpe (видам искусства), по отношению к Великой Отечественной войне.

Полученная информация позволяет социологам выявлять социальное настроение населения в отношении социально-экономической и политической ситуации в Республике Беларусь. Более того, благодаря систематически получаемой информации учеными могут строиться достаточно точные прогнозы о том, как изменится такого рода настроение у граждан Республики Беларусь.

Некоторые вопросы довольно показательны и имеют важное значение для понимания существующих социальных настроений в обществе. Таковы, например, вопросы, с помощью которых измеряется уровень доверия к довольно широкому спектру социальных институтов (Национальному собранию Республики Беларусь, Совету министров Республики Беларусь, Конституционному суду Республики Беларусь, Президенту Республики Беларусь, местным органам власти, администрации своего предприятия, официальным профсоюзам, независимым профсоюзам, политическим партиям, государственным и негосударственным СМИ, органам госбезопасности, судебным органам, налоговым органам, милиции, церкви, армии).

И конечно, существует необходимость в ежегодной оценке и изучении динамики изменений ценностных ориентаций жителей Рес- публики Беларусь. Для решения поставленной задачи в анкету социологического мониторинга ежегодно включаются такие вопросы: «Какие проблемы волнуют вас больше всего?»фокусирует внимание исследователя на различных сферах жизни респондента (личная безопасность, внедрение современных технологий, жилищная проблема, интернет-безопасность, инфляция, качество медицинского обслуживания, распространение наркомании и алкоголизма, тарифы на коммунальные услуги и некоторые другие); «Что для Вас в жизни является наиболее важным?» (богатство, вера, власть, дети, долг перед Родиной, дружба, душевный комфорт, здоровье, знания, работа, любовь и многие другие индикаторы).

В ходе реализации мониторинга ученые Института социологии НАН Беларуси имеют возможность не только давать ежегодную оценку социально-экономической, политической ситуации в стране, но и анализировать динамику данных процессов во времени, а также строить прогнозные оценки. Эта информация позволяет органам власти различного уровня корректировать свою работу.

В социологический мониторинг, который проводит Институт социологии, периодически включаются вопросы, которые необходимо изучить в данный конкретный момент времени. Такие вопросы важны не только для одномоментного анализа, но и для рассмотрения их в «связке» с основными блоками анкеты. Так, например, в последнее время в Беларуси вместе с развитием информационных технологий и техническим прогрессом стала широко развиваться такая сфера занятости, как фриланс [Веремейчик 2018]. Эта ситуация вызвала интерес социологов, так как изучение нестандартной занятости дает возможность анализировать институциональные возможности личной организации трудовой деятельности, формирование новой социальной группы, специфические способы жизнедеятельности данной категории работников и некоторые другие аспекты новых форм труда. В связи с этим в 2018 г. в инструментарий мониторинга вошли вопросы, касающиеся данной сферы жизни: «Занимаетесь ли Вы фрилансерской деятельностью?», «Какие риски для себя Вы видите, занимаясь фрилансерской деятельностью?», «Если не занима- 
етесь, то хотели бы заниматься фрилансом в будущем?». Ценность такого анализа заключается еще и в том, что эта проблема может быть рассмотрена в совокупности со всеми вопросами, касающимися традиционных форм труда («Что для Вас важно в работе?», «Насколько Вы удовлетворены: занимаемой должностью, содержанием своей работы, условиями труда, режимом работы, размером заработной платы» и т. д.), что дает возможность более комплексного исследования различных форм трудовой деятельности.

Еще одним ярким примером формирования анкеты социологического мониторинга являются вопросы, включенные в анкеты в 2018 г. и касающиеся малой родины. В Беларуси 2018-2020 гг. пройдут под знаком Года малой родины, согласно указу № 247 , подписанному Президентом Беларуси [Указ Президента Республики Беларусь от 20 июня 2018 г. ... web]. Документ принят в целях стимулирования социально-экономического развития регионов, формирования активной гражданской позиции у населения, сохранения историко-культурного и духовного наследия. В связи с этим у социологов возникла необходимость в изучении того, какое значение имеет малая родина для граждан Республики Беларусь. С этой целью в инструментарий были включены такие вопросы, как: «В какой мере Вы чувствуете привязанность к месту рождения, отчему дому, родной земле, стране Беларуси?», «Что для Вас значит быть патриотом Беларуси?», «Чем для Вас является понятие "Родина"?», «Одинаковы ли для Вас понятия "Родина" и “малая родина"?», «Если Вы считаете себя патриотом своей малой родины, то в чем это проявляется?», «Как Вы считаете, что в первую очередь следует предпринять, чтобы Ваша малая родина стала еще краше и привлекательнее?» и др. При помощи анализа этих вопросов были разработаны рекомендации по развитию регионов.

Математический анализ динамики показателей, отслеживаемых в мониторинговом исследовании, потребовал решения ряда методических и технологических задач. Основным средством анализа данных в Институте социологии НАН Беларуси в настоящее время служит разработанный в Институте пакет про- грамм «Социология и статистика». Однако этот пакет не содержит функций для динамического анализа, предполагающего необходимость однотипных расчетов по базам данных многих исследований. Кроме того, в данный момент происходит активное проникновение современных подходов к анализу данных (Data Mining, Machine Learning [Attewell, Monaghan, Kwong 2015; Hindman 2015]) в сферу социологических исследований. С учетом этого в Институте разработана и продолжает развиваться методика и технология проведения анализа данных, основанная на использовании языка программирования Python и программных библиотек к нему. В результате, с одной стороны, существенно повысилась оперативность проведения анализа данных мониторинга, а с другой - создана платформа, позволяющая исследовать возможности применения новых аналитических процедур и после апробации включать эти процедуры в состав постоянно применяемых исследовательских инструментов. Это обеспечит поддержание методического и технологического анализа данных на уровне современных требований.

Немаловажным фактором получения релевантных данных является способ формирования выборочной совокупности. На данный момент в Институте при проведении мониторингового исследования применяется случайная многоступенчатая территориальная выборочная совокупность с контролем квот на последнем этапе [Шавель, Бородачёва, Леонов 2001].

Для построения более точной модели, отражающей структуру белорусского общества, учитывается административно-территориальное деление Республики, зональная принадлежность населенного пункта, а также демографическая структура выделяемых зон. Зона - группа городских населенных пунктов, связанных между собой определенной общей характеристикой. Сельские населенные пункты входят в определенную зону в зависимости от типа районного центра, которому подчинены. Исходя из этого в основе выборочной совокупности лежит стратификация всех населенных пунктов по трем признакам:

- регион;

- тип населенного пункта;

- зона. 


\section{БЕЛОРУССКАЯ АКАДЕМИЧЕСКАЯ СОЦИОЛОГИЯ}

В настоящее время территория Республики Беларусь делится на 6 областей (Брестская, Витебская, Гомельская, Гродненская, Минская и Могилевская) и 118 районов. Каждая область уникальна по своему демографическому составу, уровню развития региона, доступности к ресурсной базе и т. д. Поэтому в выборочную совокупность попадают все области с учетом численности населения. На 1 января 2018 г. по данным Национального статистического комитета Республики Беларусь в ней проживало 9 491,8 тыс. человек, из них в Минске - 1 982,4 тыс. [Численность... web] (рис. 1).

Поскольку численность населения г. Минска превышает численность населения любой области Беларуси (Минская область рассматривается без г. Минска), то при конструировании выборочной совокупности учитывается 7 регионов, 6 областей и г. Минск.

На второй ступени стратификации учитывается зональная принадлежность населенного пункта (сельские населенные пункты относятся к зоне своего райцентра). В Беларуси выделяется 5 зон:

- 1-я зона-областные центры и г. Минск (это города с численностью населения более 250 тыс. чел.);

- 2-я зона - крупные города с численностью населения 100-250 тыс. чел.;
- 3-я зона - большие города с численностью населения 50-100 тыс. чел.;

- 4-я зона - городские населенные пункты с численностью населения 10-50 тыс. чел. (в основном состоит из районных центров);

- 5-я зона - городские населенные пункты с численностью населения менее 10 тыс. чел. и поселки городского типа.

Зональная структура городских населенных пунктов Беларуси представлена на рисунке 2.

На следующей ступени стратификации учитывается распределение жителей областей по типу их населенного пункта, то есть разделение их на городских и сельских жителей. На 1 января 2018 г. в Беларуси в городах и поселках городского типа проживало 7,4 млн чел., в сельских населенных пунктах $-2,1$ млн человек. При этом доля сельских жителей в каждой области варьируется от 19,6 \% в Могилевской области до 43,5 \% в Минской области (без г. Минска). В целом по Беларуси в городах проживает приблизительно 78 \% населения. Структура населенных пунктов Республики по типу населенного пункта (городской, сельский) с учетом региональной принадлежности представлена на рисунке 3.

После того как выделены страты с учетом региона, зоны и типа населенного пункта, случайным образом отбираются населенные пункты, в которых будет проводиться опрос.

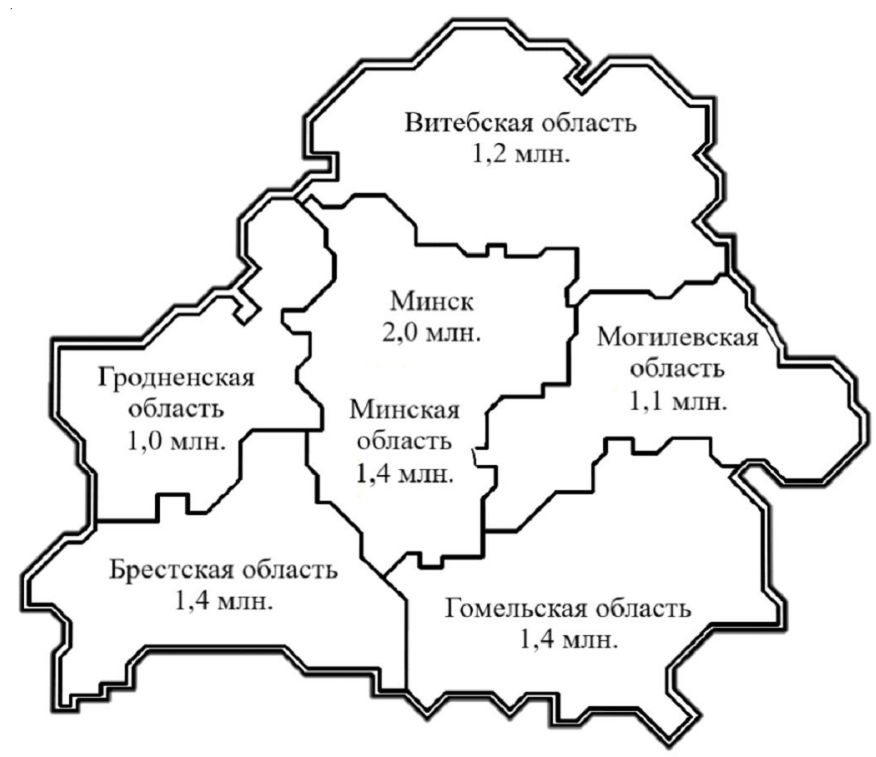

Рис. 1. Области Беларуси и численность населения по регионам 
Количество населенных пунктов зависит от числа потенциальных респондентов в конкретной страте.

Для проведения опроса населения непосредственно в отобранных населенных пунктах используется маршрутная выборка с контролем квот по трем признакам: пол, возраст и образование. Квотное задание построено таким образом, что оно репрезентирует генеральную совокупность каждой выделенной страты по указанным параметрам. В данном случае квотное задание используется как приближенное - помимо соблюдения правил маршрутной выборочной совокупности, интервьюер по возможности старается «попасть» в квотное задание. Такой подход не вредит случайному отбору, но при этом помогает соблюсти необходимые демографические показатели.

Схема конструирования выборочной совокупности представлена на рисунке 4.

Объем выборочной совокупности, используемый при проведении социологическо-

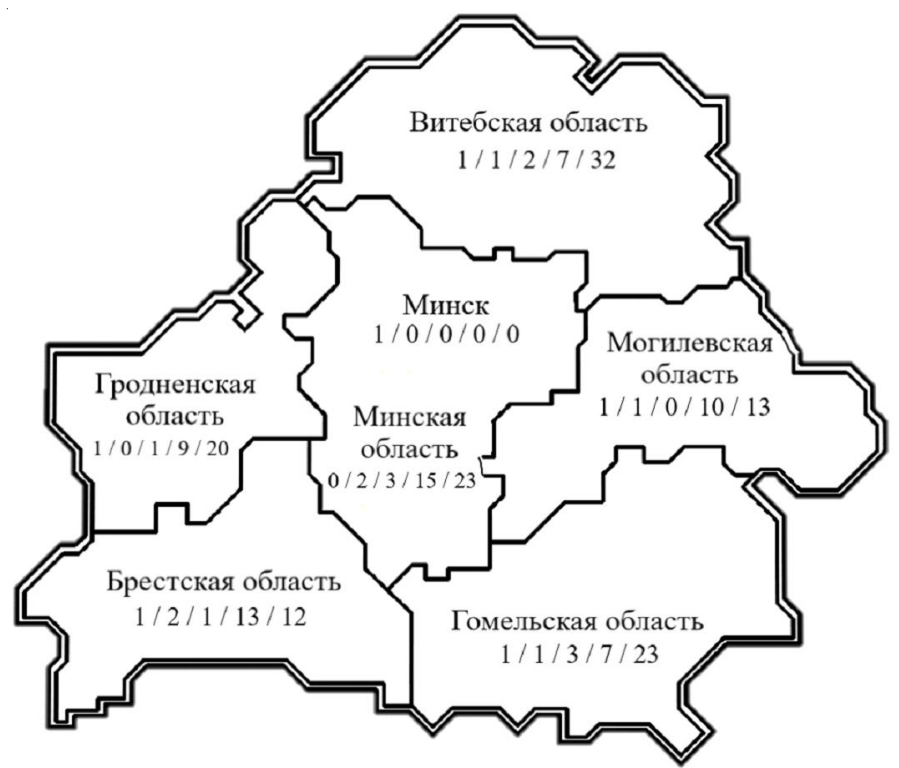

Рис. 2. Зональная структура городских населенных пунктов Беларуси (представлено число населенных пунктов по зонам: 1-я зона / 2-я зона / 3-я зона / 4-я зона / 5-я зона)

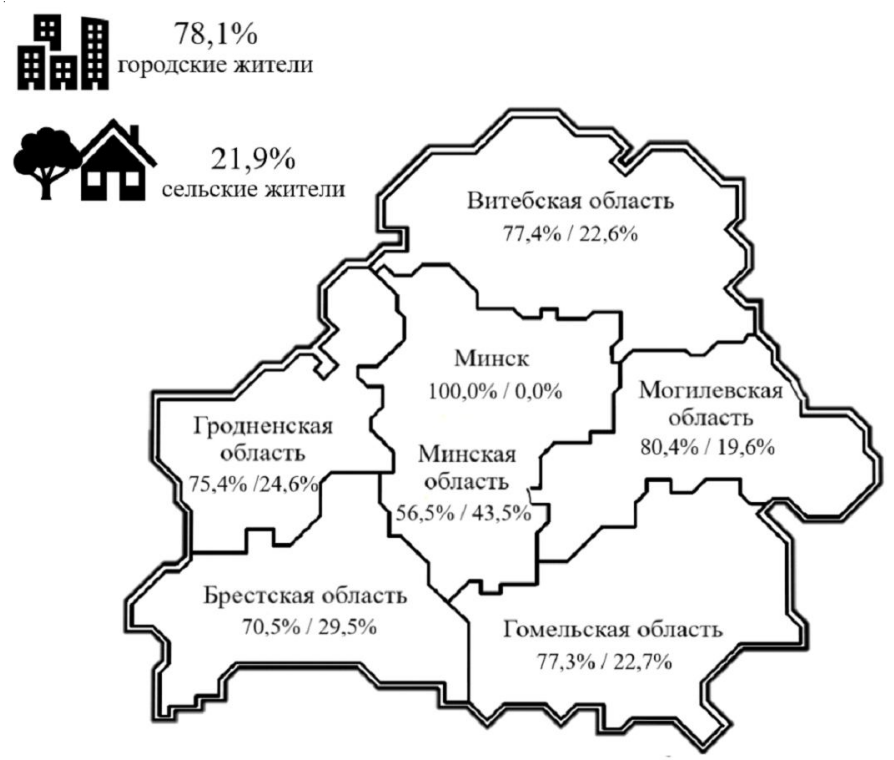

Рис. 3. Структура населенных пунктов Беларуси по типу населенного пункта (городское население / сельское население) 


\section{БЕЛОРУССКАЯ АКАДЕМИЧЕСКАЯ СОЦИОЛОГИЯ}

го мониторинга, составляет 2100 респондентов. Такой объем позволяет говорить о полученном результате с максимальной погрешностью $\pm 2,1 \%$ при уровне значимости 0,05, и при этом исследователь имеет во3можность проведения сравнительного анализа различных групп.

Изучая именно динамику какого-либо процесса или явления, можно выявить довольно интересные ситуации, связанные с данным процессом или явлением как непосредственно, так и опосредованно. Например, глядя на динамику данных об источниках получения информации, можно заметить, что в 2017 г. значительный скачок произошел по двум типам источников: «периодические печатные издания» и «от родственников, друзей, коллег и т. п.» (рис. 5). Если бы это был единичный (разовый) замер, то мы бы увидели лишь про- центное распределение ответов респондентов для каждого источника информации, которые могли бы сравнить между собой. Мониторинговое исследование показывает предпочитаемые источники информации в динамике, поэтому можно проследить тенденцию развития процесса или явления.

Обнаружив значительное увеличение ответов респондентов при выборе двух источников получения информации («периодические печатные издания» и «от родственников, друзей, коллег и т. п.»), мы попытались это объяснить, соотнеся с событиями, происходившими в Беларуси в тот период. Так, в начале 2017 г. (февраль - март) в Республике прошли акции протеста против декрета № 3 «О предупреждении социального иждивенчества» (Закон «о тунеядстве»). Эти события способствовали более активному

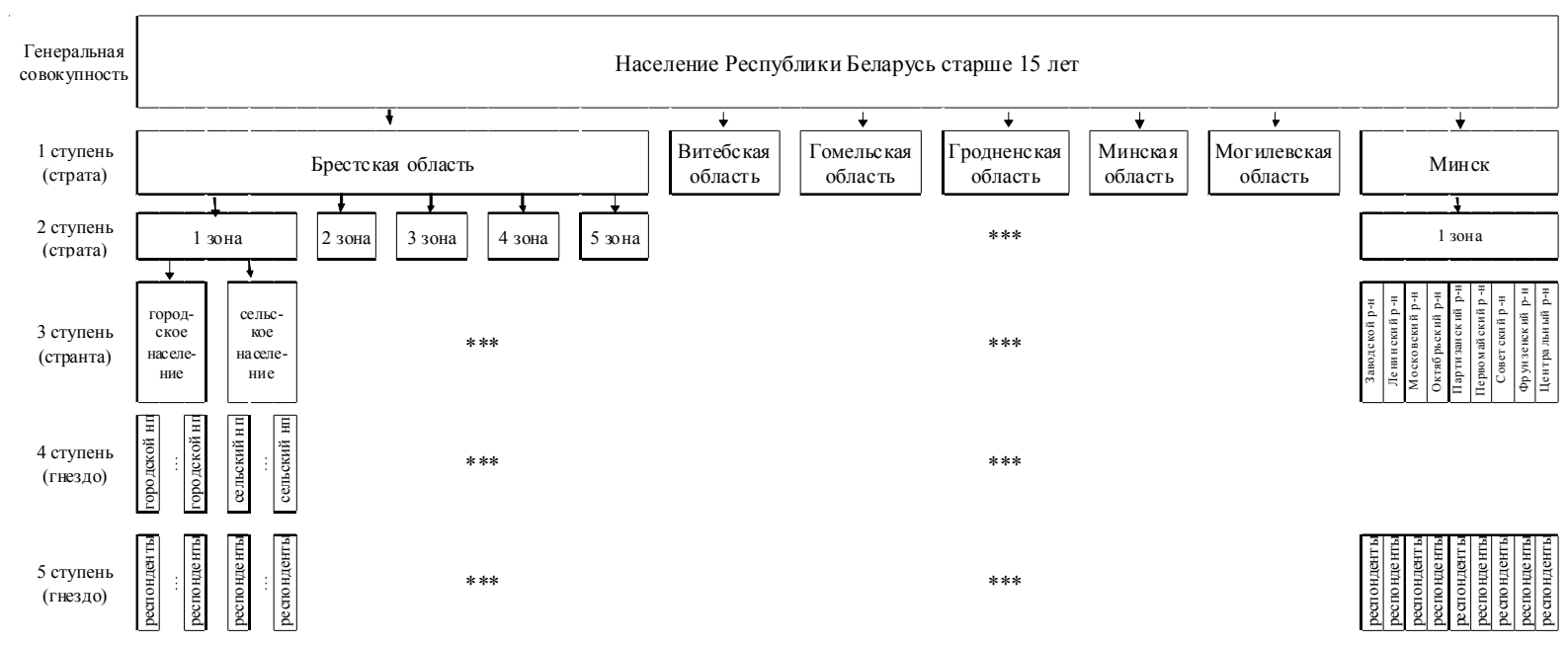

Рис. 4. Схема построения выборочной совокупности

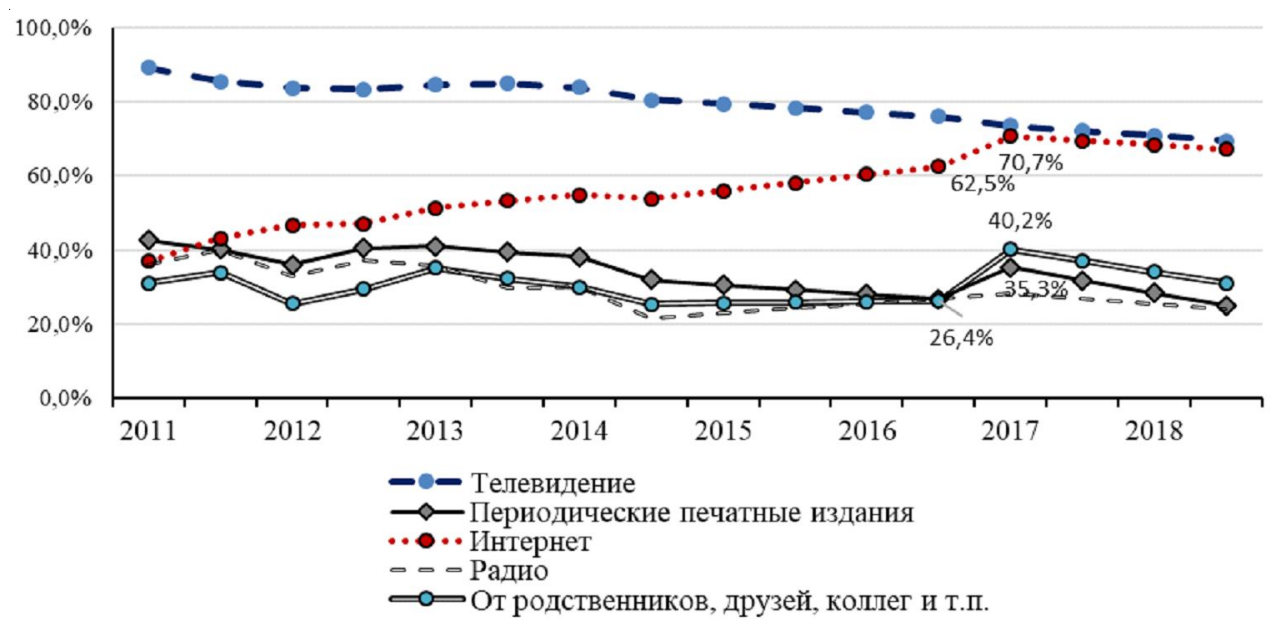

Рис. 5. Распределение ответов на вопрос: «Из каких источников Вы обычно получаете информацию?» 
поиску работу. Примечательно, что неофициальное издание этого Указа (2 апреля 2015 г.) [Декрет Президента Республики Беларусь от 2 апреля 2015 г. ... web], а именно последствия его исполнения привели к активным поискам работы населением.

Другим моментом является то, что усиленный поиск работы населением происходил по двум основным каналам - это «периодические печатные издания» и «от родственников, друзей, коллег и т. п.». Как видно из рисунка 5, на вопрос: «Из каких источников Вы обычно получаете информацию?» - процент ответивших «из периодических печатных изданий» с 2014 г. шел на спад и достиг $26,4 \%$ в конце 2016 г., а уже в начале 2017 г. вырос до 35,3 \%. Аналогичная ситуация была и с долей ответивших «от родственников, друзей, коллег и т. п.», которая с 2011 г. варьировалась от 25 до $30 \%$, а в начале 2017 г. выросла сразу до $40,2 \%$. Таким образом, можно сказать, что население Беларуси в критических ситуациях ищет себе работу через печатные источники информации и по своим социальным связям.

Можно также отметить небольшой скачок такого источника информации, как Интернет (c 62,5 до 70,7 \%), однако этот показатель на протяжении всего рассматриваемого периода показывает планомерный рост, поэтому сказать, что процент выборов сетевого источника вырос из-за поиска информации по работе, - нельзя.

Таким образом, социологический мониторинг показывает тенденции изменения какого-либо процесса или явления, а также фиксирует «всплески», которые могут привести к более глубокому описанию реальной ситуации.

Как следует из вышесказанного, мониторинг позволяет решать следующие исследовательские задачи:

- регулярное получение одномоментного социологического среза состояния общества с малым шагом по времени;

- отслеживание тенденций изменения этого состояния, что позволяет делать прогноз развития общества;

- фиксация и анализ резких изменений, что является как мотивом, так и средством изучения более глубоких закономерностей общественного развития.
Проведение социологического мониторинга имеет неоспоримое эвристическое значение. Его реализация позволяет не только обеспечивать субъекты государственного управления актуальной информацией для принятия стратегических решений, но и осуществлять социальное предвидение, наращивать базис научных школ, функционирующих в Институте социологии НАН Беларуси.

\section{СПИСОК ЛИТЕРАТУРЫ}

Веремейчик 2018 - Веремейчик T.B. Трансформация занятости в сфере услуг // Стратегия развития экономики Беларуси: вызовы, инструменты реализации и перспективы: материалы Междунар. науч.-практ. конф. (20-21 сент. 2018 г., г. Минск). В 2 т. Т 2. Минск: Право и экономика, 2018. С. 111-114.

Грицанов и др. 2003 -Грицанов А.А., Абушенко В.Л., Евелькин Г.М., Соколова Г.Н., Терещенко О.В. Социология: Энциклопедия. Минск: Книжный Дом, 2003.

Декрет Президента Республики Беларусь от 2 апреля 2015 г. ... web-Декрет Президента Республики Беларусь от 2 апреля 2015 г. № 3 «О предупреждении социального иждивенчества» [Официальный Интернет-портал Президента Республики Беларусь] // http://president.gov.by/ru/official_ documents_ru/view/dekret-3-ot-2-aprelja-2015-g$11135 /$.

Левашов 2006 - Левашов В.К. Мониторинг социально-политической устойчивости общества // Социология власти. 2006. № 3. С. 5-20.

Указ Президента Республики Беларусь от 20 июня 2018 г. ... web- Указ Президента Республики Беларусь от 20 июня 2018 г. № 247 «О проведении Года малой родины» [Официальный Интернетпортал Президента Республики Беларусь] // $\mathrm{http}: / /$ president.gov.by/ru/official_documents_ru/ view/ukaz-247-ot-20-ijunja-2018-g-18965/.

Фарман 2012 - Фарман И.П. Мониторинг как метод исследования и представления знаний // Философия науки и техники. 2012. № 1. С. 256-269.

Численность... web - Численность населения по областям и г. Минску [Национальный статистический комитет Республики Беларусь] // http:/ /www.belstat.gov.by/ofitsialnaya-statistika/ solialnaya-sfera/naselenie-i-migratsiya/naselenie/ godovye-dannye/.

Шавель, Бородачёва, Леонов 2001 - Шавель С.А., Бородачёва Е.М., Леонов Н.Н. Методологическое обоснование республиканской репрезентативной выборки. Минск: БТН-информ, 2001. 
Шадрина 2010 - Шадрина Л.Ю. Социологический мониторинг как средство информационного сопровождения оценки эффективности социальных технологий // Известия Российского государственного педагогического университета им. А.И. Герцена. 2010. № 126. C. 319-325.

Attewell, Monaghan, Kwong 2015 - Attewell P., Monaghan D.B., Kwong D. Data Mining for the Social Sciences: An Introduction. Los Angeles: University of California Press, 2011.

Hindman 2015 - Hindman M. Building Better Models: Prediction, Replication, and Machine Learning in the Social Sciences // The Annals of the American Academy of Political and Social Science. 2015. Vol. 659. P. 48-62.

\section{REFERENCES}

Veremeychik T.V., 2018. Transformation of employment in service trade. The Strategy of development of economy of Belarus: calls, instruments of realization and prospect: materials of the International scientific and practical conference (on September 20-21, 2018, Minsk), vol. 2, pp. 111-114.

Gritsanov A.A., Abushenko V.L., Evelkin G.M., Sokolova G.N., Tereshchenko O.V., 2003. Sotsiologiya: Encyclopedia. Minsk: Book House.

Decree of the President of Republic Belarus, on April 2, 2015, No. 3 "About prevention of social dependence". Official Internet portal of the President of Republic of Belarus. URL: president.gov.by/ru/official_documents_ru/ view/dekret-3-ot-2-aprelja-2015-g-11135/.

Levashov V.K., 2006. Monitoring of socio-political stability of society. Sociology of the power, no. 3, pp. 5-20.

Presidential decree of Republic Belarus, on June 20, 2018, No. 247 "About carrying out Year of the small homeland". Official Internet portal of the President of Republic of Belarus. URL: president.gov.by/ru/official documents ru/ view/ukaz-247-ot-20-ijunja-2018-g-18965/.

Pharman I.P., 2012. Monitoring as method of a research and representation of knowledge. Philosophy of science and technology, no. 1, pp. 256-269.

Population on areas and Minsk. National statistical committee of Republic of Belarus. URL: www.belstat.gov.by/ofitsialnaya-statistika/ solialnaya-sfera/naselenie-i-migratsiya/ naselenie/godovye-dannye/.

Shavel S.A., Borodacheva E.M., Leonov N.N., 2001. Methodological justification of republican representative selection. Minsk: BTN-inform.

Shadrina L.Yu., 2010. Sociological monitoring as means of information maintenance of assessment of efficiency of social technologies. News of the Russian state pedagogical university of A.I. Herzen, no. 126, pp. 319-325.

Attewell P., Monaghan D. B., Kwong D., 2015. Data Mining for the Social Sciences: An Introduction. Los Angeles, University of California Press.

Hindman M., 2015. Building Better Models: Prediction, Replication, and Machine Learning in the Social Sciences. The Annals of the American Academy of Political and Social Science, vol. 659, pp. 48-62.

\section{Information about the Authors}

Nikolai N. Leonov, Candidate of Sciences (Physics and Mathematics), Leading Researcher, Mathematical and Methodological Support, Institute of Sociology of the National Academy of Sciences of Belarus, Surganova St., 1/2, 220072 Minsk, Republic of Belarus, nick.leonov@gmail.com, https://orcid.org/0000-0001-8085-0571

Elena M. Borodacheva, Head of the Mathematical and Methodological Support, Institute of Sociology of the National Academy of Sciences of Belarus, Surganova St., 1/2, 220072 Minsk, Republic of Belarus, helenb@tut.by, https://orcid.org/0000-0002-6916-6768

Vera M. Zrazikova, Researcher, Mathematical and Methodological Support, Institute of Sociology of the National Academy of Sciences of Belarus, Surganova St., 1/2, 220072 Minsk, Republic of Belarus, zraza@tut.by, https://orcid.org/0000-0003-3127-6125

Nadezhda N. Malinovskaya, Junior Researcher, Mathematical and Methodological Support, Institute of Sociology of the National Academy of Sciences of Belarus, Surganova St., 1/2, 220072 Minsk, Republic of Belarus, malina_raz14@yahoo.com, https://orcid.org/0000-0003-3482-7922 


\section{Информация об авторах}

Николай Николаевич Леонов, кандидат физико-математических наук, ведущий научный сотрудник отдела математического и методического обеспечения социологических исследований, Институт социологии НАН Беларуси, ул. Сурганова, 1/2, 220072 г. Минск, Республика Беларусь, nick.leonov@gmail.com, https://orcid.org/0000-0001-8085-0571

Елена Михайловна Бородачёва, заведующая отделом математического и методического обеспечения социологических исследований, Институт социологии НАН Беларуси, ул. Сурганова, 1/2, 220072 г. Минск, Республика Беларусь, helenb@tut.by, https:/orcid.org/0000-0002-6916-6768

Вера Михайловна Зразикова, научный сотрудник отдела математического и методического обеспечения социологических исследований, Институт социологии НАН Беларуси, ул. Сурганова, 1/2, 220072 г. Минск, Республика Беларусь, zraza@tut.by, https://orcid.org/0000-0003-3127-6125

Надежда Николаевна Малиновская, младший научный сотрудник отдела математического и методического обеспечения социологических исследований, Институт социологии НАН Беларуси, ул. Сурганова, 1/2, 220072 г. Минск, Республика Беларусь, malina_raz14@yahoo.com, https://orcid.org/0000-0003-3482-7922 